\title{
AKT2 drives cancer progression and is negatively modulated by miR-124 in human lung adenocarcinoma
}

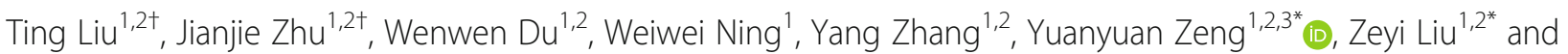
Jian-An Huang ${ }^{1,2,4^{*}}$

\begin{abstract}
Background: AKT2 is highly expressed in many human cancers, including non-small cell lung cancer (NSCLC). Accumulating evidence has also revealed that AKT2 can promote NSCLC cell proliferation and metastasis. However, the involved mechanism remains unclear. Herein, our study mainly explored the function of AKT2 during cancer progression and uncovered a new post-transcriptional mechanism of AKT2 expression in lung adenocarcinoma (LUAD).
\end{abstract}

Methods: Quantitative real-time (qRT-PCR), western blot and immunohistochemistry (IHC) assays were performed to detect the expression of AKT2 and other proteins. Cell counting kit-8 (CCK-8), colony formation and EdU assays were performed to assess cell proliferation. Flow cytometry analysis was used to detect changes in the cell cycle and apoptosis. Transwell assays were used to evaluate cell migration and invasion. Additionally, a luciferase reporter assay and western blotting were employed to assess miR-124 targeting of AKT2. Xenograft mouse model was used to observe the role of miR-124/AKT2 axis on the occurrence and development of LUAD.

Results: We showed that AKT2 was highly expressed in NSCLC tissues and closely related to the poor prognosis of LUAD patients. Moreover, AKT2 affected LUAD cell proliferation, migration and invasion by regulating the cell cycle and promoting the occurrence of epithelial-mesenchymal transition (EMT) and the expression of matrix metalloproteinases (MMPs). In addition, we demonstrated that miR-124 overexpression downregulated AKT2 expression by binding to the $3^{\prime}$-untranslated region (3'- UTR) of AKT2 and thus inhibited the occurrence and development of LUAD in vivo and in vitro.

Conclusions: Our results suggest that miR-124 overexpression can negatively regulate AKT2 and thus inhibit the progression of LUAD. Therefore, the miR-124/AKT2 axis may serve as a potential target for novel therapies for LUAD.

Keywords: Lung adenocarcinoma, AKT2, Proliferation, Migration, Invasion, miR-124

\footnotetext{
*Correspondence: zengyuanyuan0921@163.com; liuzeyisuda@163.com;

huang_jian_an@163.com

${ }^{\dagger}$ Ting Liu and Jianjie Zhu contributed equally to this work.

'Department of Respiratory Medicine, the First Affiliated Hospital of Soochow University, Suzhou 215006, China

Full list of author information is available at the end of the article
}

(C) The Author(s). 2020 Open Access This article is licensed under a Creative Commons Attribution 4.0 International License, which permits use, sharing, adaptation, distribution and reproduction in any medium or format, as long as you give appropriate credit to the original author(s) and the source, provide a link to the Creative Commons licence, and indicate if changes were made. The images or other third party material in this article are included in the article's Creative Commons. licence, unless indicated otherwise in a credit line to the material. If material is not included in the article's Creative Commons licence and your intended use is not permitted by statutory regulation or exceeds the permitted use, you will need to obtain permission directly from the copyright holder. To view a copy of this licence, visit http://creativecommons.org/licenses/by/4.0/ The Creative Commons Public Domain Dedication waiver (http://creativecommons.org/publicdomain/zero/1.0/) applies to the data made available in this article, unless otherwise stated in a credit line to the data. 


\section{Introduction}

Lung cancer has the highest mortality rate among cancer-related diseases based on the latest worldwide report [1]. Non-small cell lung cancer (NSCLC) accounts for approximately $85 \%$ of cases among 1.8 million newly diagnosed patients [1, 2]. Lung adenocarcinoma (LUAD) and squamous cell carcinoma (LUSC) are two main subtypes. Despite advances in the diagnosis and treatment of NSCLC, the five-year survival rate is still poor [3]. Therefore, a deeper understanding of the pathogenesis of lung cancer is urgently needed.

AKT (protein kinase B, PKB) family members are well known for their roles in regulating tumorigenesis and development [4]. AKT1, AKT2 and AKT3 belong to the AKT family. All the AKT family members contain similar protein structures, such as the $\mathrm{N}$-terminal, $\mathrm{PH}$ domain, catalytic domain and $\mathrm{C}$-terminal regulatory domain, although the members are encoded by different genes [5]. Tissue distributions are varied among these family members. AKT1 and AKT2 are widely expressed in human tissues, while AKT3 is mainly distributed in brain tissue [4]. Among these three, AKT2 is much more closely associated with cancer cell metabolism, proliferation, cell survival, metastasis, angiogenesis and drug resistance [6]. In breast cancer, inhibition of AKT2 can not only effectively prevent the transformation of mesenchymal non-cancer stem cells (non-CSC) into epithelial cells but also reduce the invasive and colony formation abilities of non-CSC and CSC [7]. In colon cancer, the expression of AKT2 can affect the DNA repair ability and radiosensitivity [8]. In NSCLC, AKT2 can affect tumor cell survival and chemotherapy sensitivity [9]. Thus, AKT2 is considered a promising target for cancer-targeted therapy.

MicroRNAs are single strand small noncoding RNAs that partially or completely bind to the 3 '-UTR region of target mRNAs to modulate gene expression, resulting in the regulation of proliferation, differentiation, apoptosis and metastasis in cancer cell progression [10, 11]. MiR-124 expression has been reported to be widely downregulated in many cancers, such as breast cancer, colon cancer, glioma, lymphoma, NSCLC and so on [12-16]. Accumulating reports have demonstrated the roles of miR-124 in the occurrence and development of a variety of tumors. In neuroblastoma, miR-124 induces neuroblastoma differentiation by downregulating the expression of the transcription factor ELF4 [17]. In bladder cancer, miR-124 negatively modulates EDNRB to suppress proliferation and induce apoptosis in tumor cells [18]. Although miR-124 expression was suggested to be downregulated in NSCLC, the molecular mechanism underlying the involvement of the miR-124/AKT2 axis in mediating cell proliferation and metastasis is not fully understood, especially in LUAD subtypes $[16,19,20]$.
In our current study, we proved that AKT2 expression was upregulated in NSCLC tissues. Knockdown of AKT2 expression could attenuate cell proliferation via cell cycle arrest. Moreover, migration was also inhibited by reversing the EMT process and regulating the MMP family. In addition, we confirmed that miR-124 could directly target the $3^{\prime}$-UTR of AKT2 and thus inhibit AKT2 expression in vivo and in vitro. Taken together, our data identify a novel mechanism by which the miR124/AKT2 axis mediates carcinogenesis and provide new potential therapeutics for LUAD.

\section{Materials and methods}

Patients and tissue samples

Tissue samples from 45 NSCLC patients and matched noncancerous tissue samples collected between 2012 and 2016 were obtained from the First Affiliated Hospital of Soochow University. All cases were confirmed by experienced clinicians and pathologists, and no patient received any relevant treatment before sampling. All collected samples were stored at $-80^{\circ} \mathrm{C}$. Each patient involved in the research signed a written informed consent form, and this study was approved by the Ethics Committee and Institutional Review Board of the First Affiliated Hospital of Soochow University. All the methods used in the study are based on the approved guidelines.

\section{Immunohistochemisty (IHC) staining}

Tissue samples were fixed with $4 \%$ paraformaldehyde and embedded in paraffin. After baking, deparaffinization and rehydration, slides were immersed in $3 \% \mathrm{H}_{2} \mathrm{O}_{2}$ for $15 \mathrm{~min}$, heated at $95^{\circ} \mathrm{C}$ for $25 \mathrm{~min}$ and cooled at room temperature. These sections were then incubated with an anti-AKT2 polyclonal antibody (diluted 1:200, Proteintech, 17,609-1-AP) and an anti-KI67 antibody (diluted 1:400, Cell Signaling Technology, 9449) at $4{ }^{\circ} \mathrm{C}$ overnight and visualized using diaminobenzidine as the chromogenic substrate (DAB kit, ZSGB-Biotechnology Co., Ltd., Beijing, China). Finally, the sections were counterstained with hematoxylin and examined by optical microscopy. The staining results for AKT2 were evaluated based on the staining intensity and the percentage of positively stained cells.

\section{Cell culture}

Cells were provided by the Cell Bank of the Chinese Academy of Sciences (Shanghai, China). RPMI 1640 medium supplemented with $10 \%$ fetal bovine serum (Gibco, Carlsbad, CA, USA), penicillin $(100 \mathrm{U} / \mathrm{ml})$ and streptomycin $(100 \mathrm{ng} / \mathrm{ml})$ was used for cell culture. All cell lines were maintained in $37^{\circ} \mathrm{C}$ humidified incubators with $5 \% \mathrm{CO}_{2}$. 


\section{Western blot analysis and antibodies}

Western blot analysis was performed as we described previously [21]. In this study, the antibodies used were anti-AKT2 (17609-1-AP, Proteintech, China); anti-pAKT (Ser473) (D9E), anti-AKT, anti-pErk (Thr202/Tyr202) (D13.14.4E), anti-Erk (137F5), anti-Slug (C19G7), antiMMP9 (603H), anti-MMP7 (D4H5), and anti-MMP2 (D8N9Y) (Cell Signaling Technology, Danvers, MA, USA); anti-N-cadherin and anti-vimentin (RV202) (BD Biosciences, USA); and anti- $\beta$-actin and anti-mouse or antirabbit secondary antibodies (Cell Signaling Technology). Each experiment was performed in triplicate.

\section{RNA isolation and quantitative real-time PCR analysis}

The detailed processes were performed as we previously described [22]. The primer sequences used in this study are listed in Supplementary Additional file 1 Table S1 (Sangon Biotech, Shanghai, China). MiR-124 and U6 primers were purchased from RiboBio Co. (Guangzhou, China). The CT values of $A K T 2$ mRNA and miR-124 were normalized to those of $A C T B$ mRNA and U6, respectively. The ${ }^{\Delta \Delta} \mathrm{Ct}$ method was applied to calculate the relative quantities of these mRNAs. Each experiment was performed in triplicate.

\section{MicroRNA (miRNA) and small interfering RNA (siRNA) transfection}

A549 and H1299 cells were seeded in the 6-well plates. When the cell intensity reached $60 \%$, we replaced the medium with $1.5 \mathrm{ml}$ fresh serum-free RPMI-1640 medium for $2 \mathrm{~h}$ and then $250 \mu \mathrm{l}$ serum-free medium containing $5 \mu \mathrm{l}$ Lipofectamine 2000 transfection reagents or $5 \mu \mathrm{l}$ siRNA /microRNA ( $50 \mathrm{nmol}$ per well) were mixed for $15 \mathrm{~min}$ at room temperature. Later, the above mixture was added into 6-well plates. Six hours later, the cell supernatant was changed with $2 \mathrm{ml}$ medium with 10\%FBS. After $48-72 \mathrm{~h}$ transfection, the cells were collected for further experiments. MiR-124 mimic and negative control were purchased from GenePharma (Shanghai, China). The siRNAs specific for AKT2 were provided by Shanghai GenePharma Company. The target sequences of the siRNAs were as follows: siRNA-AKT2-1: 5' -GCUCCUUCUAUUGGGUACAATT-3', siRNA-AKT2-2: 5' -GCGGAAGGAAGUCA UCAUUTT-3', and siRNA-AKT2-3: 5'-GGUUCUUCCU CAGCAUCAATT-3'.

\section{CCK-8, colony formation and EdU assays}

Cell proliferation was evaluated using Cell Counting Kit8 (Beyotime Institute of Biotechnology). Briefly, cells were cultured in 96-well plates and seeded at 3000 cells per well. At $24 \mathrm{~h}, 48 \mathrm{~h}$ and $72 \mathrm{~h}, 10 \mu \mathrm{l}$ CCK- 8 dye was added to each well and incubated at $37^{\circ} \mathrm{C}$ for $3-4 \mathrm{~h}$. Then, the absorbance was measured at $450 \mathrm{~nm}$ and $630 \mathrm{~nm}$ using a spectrophotometer (Thermo Fisher Scientific). For the colony formation assay, cells were cultured for 7-10 days until foci formed. The cells were then fixed with methanol and stained with crystal violet. For the EdU assay, we performed the experiment according to the kit instructions. A cell-light EdU Apolo567 in vitro kit was purchased from RiboBio Co. The experiments were performed in triplicate.

\section{Cell migration and invasion assays}

For the migration assay, $3 \times 10^{4}$ transfected cells suspended in medium containing $1 \%$ FBS were added to the upper chamber, and $800 \mu \mathrm{l}$ normal medium containing $10 \%$ FBS was added to the lower chamber. For the invasion assay, the upper chamber was coated with a Matrigel matrix at a 1:6 dilution (BD Science, Sparks, MD, USA). Then, 1\% FBS medium containing $5 \times 10^{4}$ tumor cells was added to the upper chamber, and $800 \mu \mathrm{l}$ $10 \%$ FBS medium was added to the lower chamber. After culturing for $24 \mathrm{~h}$, the cells were fixed with methanol, stained with crystal violet, and imaged under a microscope. The transwell chambers used in our study were purchased from BD Biosciences. Each experiment was performed independently in triplicate.

\section{Flow cytometry analysis}

For cell cycle assay, transfected tumor cells were washed with PBS, suspended in $70 \%$ ethanol and then fixed at $4{ }^{\circ} \mathrm{C}$ overnight. Then, the cells were stained with a mixed propidium iodide solution and incubated at $37^{\circ} \mathrm{C}$ for $30 \mathrm{~min}$. For apoptosis assay, transfected tumor cells were stained with an Annexin V/PI kit (Beyotime, Shanghai, China). Finally, the cells in both experiments were evaluated using a fluorescence-activated cell sorting (FACS) Caliber system (Beckman Coulter, Brea, CA, USA). Each experiment was performed independently in triplicate.

\section{Dual-luciferase reporter assay}

143-bp sequence of the 3 '-UTR of AKT2 containing the putative miR-124 binding site or mutated target site were synthesized and cloned into the pGL3 basic vector (Promega, Madison, WI, USA) which were named WT (wild-type AKT2 3'-UTR fragment) and Mut (mutant AKT2 3'-UTR fragment). A549 and H1299 cells were seeded in 24-well plates and co-transfected with WT or Mut plasmids along with either miR-NC or miR-124 mimic using Lipofectamine 2000 (Invitrogen, Carlsbad, CA, USA). At the same time, pRL-TK Renilla Luciferase Reporter Vector (Promega) was transferred into each well. After incubated for $48 \mathrm{~h}$, the cell lysates were harvested. The luciferase activity was assessed by the Dual-Luciferase Reporter Assay Kit (Promega) and then standardized with renilla luciferase activity.. Each experiment was performed independently in triplicate. 


\section{Tumorigenesis in nude mice}

Female BALB/c nude mice were obtained and bred in the Experimental Animal Center of Soochow University. In total, $2 \times 10^{6}$ A549 cells were injected subcutaneously into the mice. Fifteen days after inoculation, a miR-124 agomir (RiboBio Co.) and miR-NC agomir were used for intratumoral treatment at a dose of $2 \mathrm{nmol}$ per tumor. Intratumoral treatment was performed three times a week for a total of seven times. Xenograft tumor volume and body weight of mice were measured every 2-4 days for a total of 36 days. We used the volume measurements to evaluate the growth of tumors, and tumor volume was calculated by measuring the length and width of a xenograft tumor and using the following formula: $\left(\right.$ Volume $=$ length $\times$ width $\left.^{2}\right) / 2$.

\section{Statistical analysis}

Student's t-test was used for statistical analysis, and $P<$ 0.05 was considered significant. All statistical analyses were performed using GraphPad Prism 5.0 (GraphPad, San Diego, CA, USA) and SPSS 7.0 software (SPSS, Chicago, IL, USA). All results are presented as the mean \pm SD (standard deviation). Kaplan-Meier methods were used for survival analysis, and survival curves were compared by the log-rank test.

\section{Results}

\section{AKT2 is overexpressed in human NSCLC tissues}

First, qRT-PCR analysis was carried out to compare AKT2 mRNA expression between 45 paired NSCLC patient tissues and adjacent normal tissues. Among them, 28 NSCLC tissues exhibited higher AKT2 mRNA expression levels $(28 / 45,62.22 \%)$ than the corresponding paracancerous tissues (Fig. 1a and c; $P=0.0441$ ). Western blot analysis also showed higher AKT2 protein levels in 8 paired NSCLC tissues (Fig. $1 \mathrm{~b}, P=0.0206$ ). However, we did not find any significant associations between AKT2 mRNA expression and clinical characteristics including age, histology, lymph node metastasis status, distant metastasis status and TNM stage, but there was a difference in expression between the sexes, which needs to be further explored in large populations (Additional file 2 Table S2). In addition, to further explore the expression of AKT2 in NSCLC tissues, data from the GEO database were analyzed. As shown in Fig. 1d-f, the data extracted from GSE 10072, GSE 31210 and GSE 32863 consistently indicated that there was no significantly statistical difference of AKT2 expression in NSCLC tissues when compared to adjacent tissues, but there was an upward trend of AKT2 mRNA levels in NSCLC tissues compared with normal tissues. Data from The Tumor Immune Estimation Resource (TIMER) database (https://cistrome.shinyapps.io/timer/) showed that AKT2 was overexpressed in both LUAD and LUSC tissues (Fig. 1g). In addition, an immunohistochemistry assay similarly showed higher AKT2 protein levels in lung cancer tissues than in normal tissues (Fig. 1h). In summary, these results demonstrated that AKT2 expression was upregulated in NSCLC tissues, suggesting that AKT2 acts as an oncogene in NSCLC.

\section{Increased AKT2 expression is associated with poor prognosis in lung adenocarcinoma patients}

To further explore the prognostic significance of AKT2 in NSCLC, the public database Kaplan-Meier plotter (www.kmplot.com) was used. Data from the database showed that higher expression of AKT2 was associated with poorer overall survival (OS) (Fig. 2a, $\mathrm{HR}=1.22$, 95\% CI: $1.07-1.38, P=0.0023)$ and progression-free survival (PFS) (Fig. $2 \mathrm{~b}, \mathrm{HR}=1.82$, 95\% CI: 1.49-2.21, $P=$ 1.3e-09) in NSCLC patients. Then, we divided the data into LUAD and LUSC subtypes to further explore the correlation between AKT2 expression and the survival rates in these two subsets of patients. Interestingly, we found that AKT2 overexpression was closely related to poorer OS and PFS in LUAD (Fig. 2c and d; both $P<$ 0.05 ) but not in LUSC (Fig. 2e and f; both $P>0.05$ ). Moreover, data from the TIMER database showed results similar to those from the Kaplan-Meier plotter database. When the AKT2 expression level was divided into the top $50 \%$ and lower $50 \%$, we found that higher AKT2 expression was significantly correlated with poorer OS in LUAD patients but not in LUSC patients (Fig. $2 \mathrm{~g}$ and $\mathrm{h}$ ). Taken together, these results suggested that high AKT2 expression could be regarded as an predictive indicator for poor prognosis in LUAD patients.

\section{Knockdown of AKT2 expression suppresses tumor cell viability and arrests the cell cycle in LUAD}

From the previous clinical results and analysis, we speculated that AKT2 functions as an oncogene in LUAD. To verify this hypothesis, we first detected the AKT2 expression levels in LUAD cell lines. QRT-PCR and western blot assays showed higher AKT2 expression levels in LUAD cell lines than in lung epithelial cells (Fig. 3a and b). Then, we selected A549 and H1299 cells, which expressed relatively high AKT2 levels, for further experiments. Consequently, we silenced the expression of AKT2 with siRNAs) (Fig. 3c and d). CCK-8 and colony formation assays were performed with AKT2silenced A549 and H1299 cells. The results showed that knockdown of AKT2 expression significantly inhibited tumor cell proliferation (Fig. 3e-g). EdU staining experiments further confirmed that cell proliferation was attenuated after AKT2 knockdown (Fig. 3h). In addition, a flow cytometry assay was performed, and the results demonstrated that the percentage of cells in the G0/G1 phase was increased, and the percentage of cells in the $S$ phase was decreased in AKT2-silenced A549 and H1299 
A

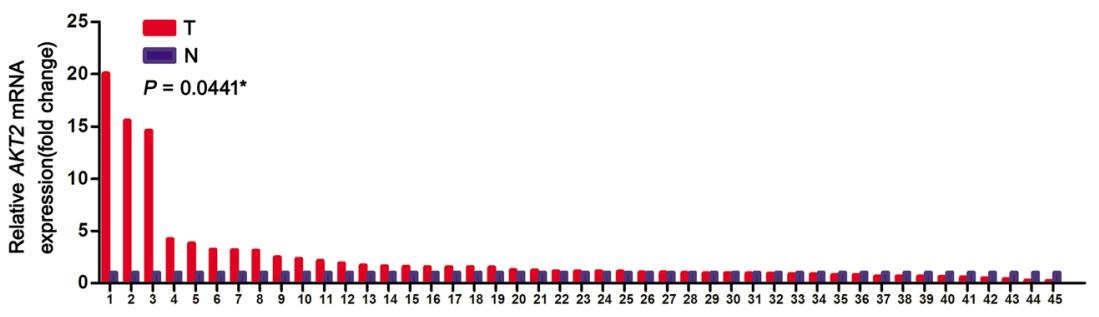

B
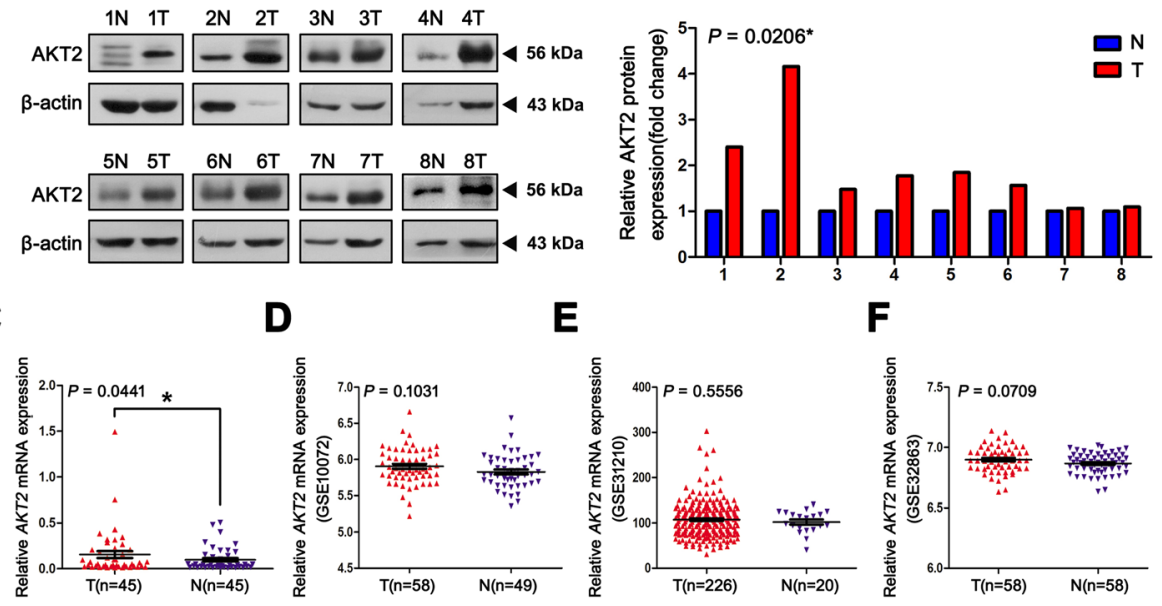

G

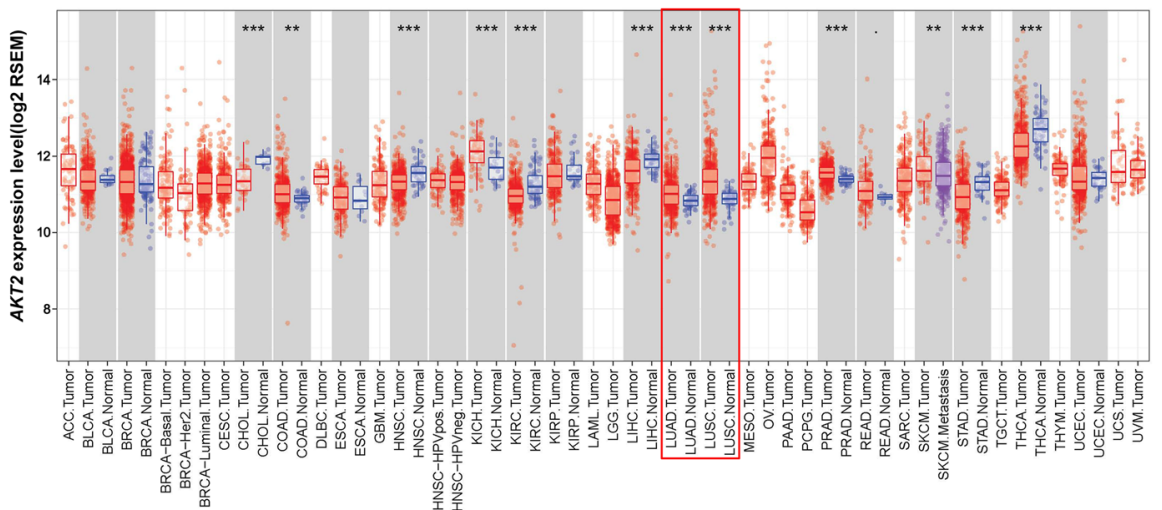

H
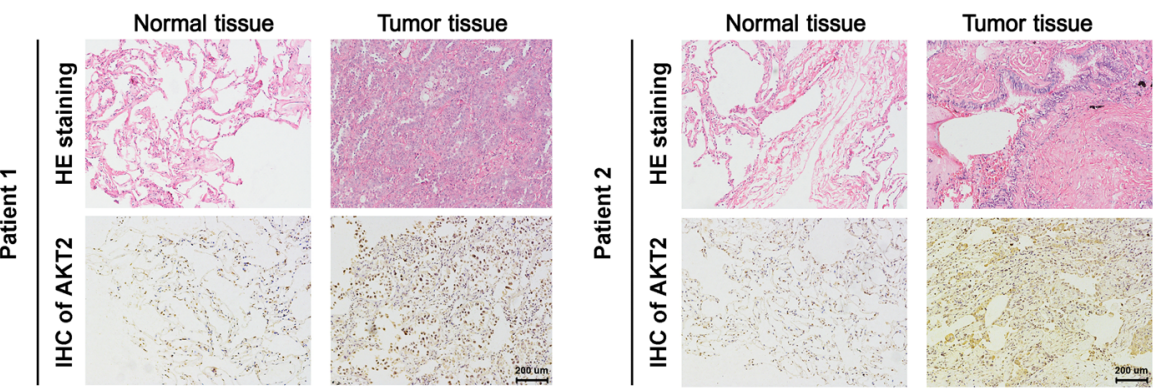

Fig. 1 (See legend on next page.) 


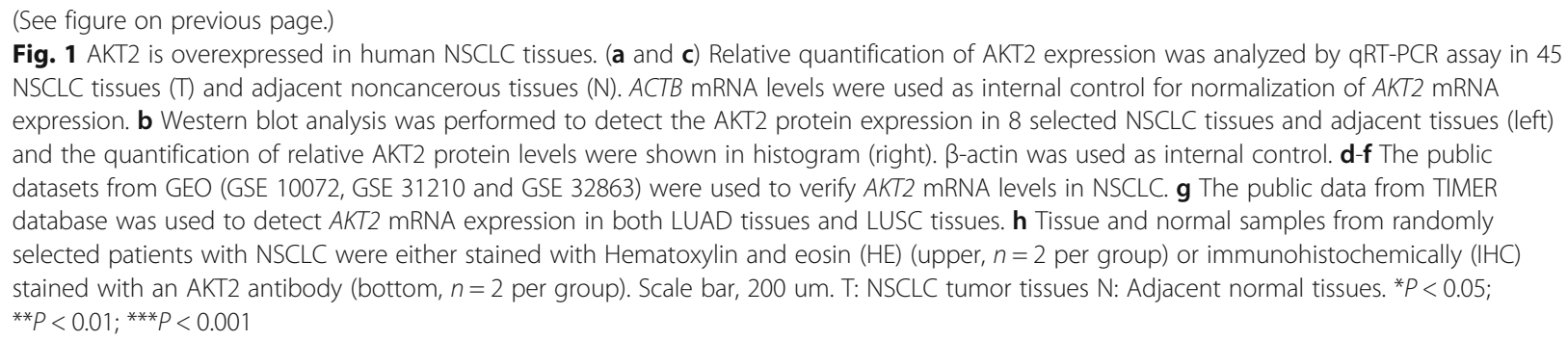

cells (Fig. 4a). However, we did not observe any effect on the apoptosis of tumor cells after inhibiting the expression of AKT2, indicating that AKT2 may control cell proliferation via cell cycle regulation (Fig. 4b).

\section{Knockdown of AKT2 expression inhibits tumor cell migration and invasion in LUAD}

Transwell assays were used to evaluate the effects of AKT2 on LUAD cell migration and invasion. After transiently silencing AKT2 gene expression, the migratory and invasive abilities of cells were inhibited by more than 50\% (Fig. 5a). Next, we used qRT-PCR (Fig. 5b) and western blotting (Fig. 5c) to explore the potential mechanism underlying AKT2-mediated metastasis and proliferation. After transfection of si-AKT2 in A549 and H1299 cells, the expression of not only EMT-related markers (N-cadherin, Vimentin and Slug) but also some matrix metalloproteinases (MMP2, MMP7, and MMP9) was significantly decreased. Additionally, phosphorylated AKT and Erk levels were dramatically decreased in AKT2-silenced A549 and H1299 cells, while the corresponding total protein levels remained unchanged. These results demonstrated that knockdown of AKT2 expression inhibited tumor cell migration and invasion in LUAD.

\section{AKT2 is a direct target of miR-124 and modulated by miR- 124}

MicroRNA/mRNA interactions are a common mechanism for regulating gene expression. To identify the putative miRNAs that account for the upregulation of AKT2 expression in LUAD, we screened four authoritative bioinformatic databases including miRDB (http://mirdb.org/ miRDB/), miRWalk (http://mirwalk.umm.uni-heidelberg. de), miRTarBase (http://mirtarbase.mbc.nctu.edu.tw/php/ index.php) and TargetScan (www.targetscan.org) (Fig. 6a). MiR-124, which has been proven to be downregulated in LUAD tissues, was selected [23]. After transfection of miR-124 mimic into A549 and H1299 cells, the expression of AKT2 decreased significantly at both the mRNA and protein levels. In contrast, miR-124 inhibitor transfection induced upregulated AKT2 expression (Fig. 6b). To further confirm that AKT2 is a direct target of miR-124, we synthesized plasmids containing the 3'-UTR region (746-
753) of AKT2, which was predicted as a potential binding site. A luciferase assay showed that miR-124 significantly inhibited the relative luciferase activity of A549 and H1299 cells transfected with the wild-type sequence, but there was no effect on cells transfected with the mutated sequence (Fig. 6c). Furthermore, we used qRT-PCR to validate miR-124 expression in 45 paired NSCLC tissues and normal lung tissues. The data showed that miR-124 expression was lower in lung cancer tissues than in adjacent normal tissues (Fig. 6d, $P=0.0421$ ). However, depending on the patient data we used, miR-124 expression showed no significant associations with clinical parameters (Additional file 2 Table S2). In addition, the correlation analysis showed that the expression of miR-124 was negatively correlated with that of AKT2 in 45 NSCLC tissues (Fig. 6e, $P=$ $0.0162, r=-0.3567)$.

Then, we investigated the effect of miR-124 on the biological behavior of LUAD cells. CCK- 8 and colony formation assays indicated that miR-124 overexpression could significantly inhibit cell proliferation in LUAD (Fig. 6f and g). Flow cytometry analysis showed that overexpression of miR-124 arrested the cell cycle in the G0/G1 phase (Fig. 6j) but had no effect on apoptosis (Fig. 6k). In addition, transwell assays showed that migratory and invasive abilities were inhibited in A549 and H1299 cells transfected with miR-124 (Fig. 6h and i). Finally, we also found that the expression levels of EMT markers, MMPs, p-AKT and p-Erk were significantly decreased at the mRNA and protein levels after miR-124 transfection (Fig. $6 \mathrm{l}$ and $\mathrm{m}$ ).

\section{MiR-124 overexpression inhibits tumor growth by suppressing the expression of AKT2 in vivo}

Finally, to further investigate the effect of miR-124 on the proliferation of LUAD cells in vivo, A549 cells were subcutaneously injected into athymic BALB/C mice, followed by intratumoral treatment with a miR-124 agomir or miR-NC agomir (Fig. 7a). Tumor growth and increases in tumor weight were sharply inhibited in the miR-124 agomir treatment group compared with the control group (Fig. 7b-d). At 36 days after tumor cell infection, we sacrificed the mice and excised the xenograft tumors. QRT-PCR was used to evaluate the expression 

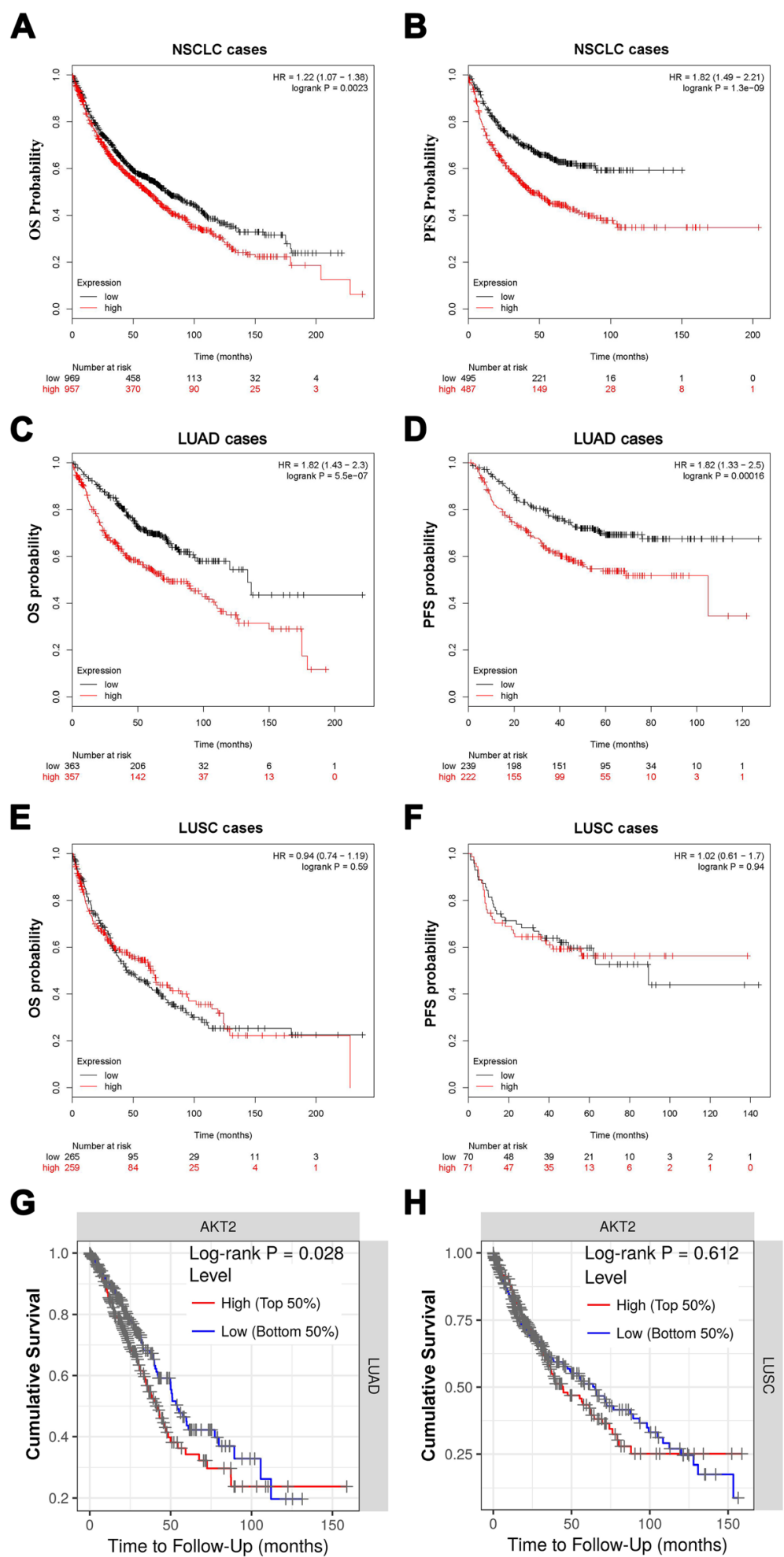

Fig. 2 Up-regulated AKT2 expression is associated with poor prognosis in LUAD patients. a and $\mathbf{b}$ Kaplan-Meier plots from Kaplan-Meier plotter shows the correlation between AKT2 expression and overall survival (a) or progression-free survival in patients with NSCLC (b). c-f Kaplan-Meier plotter data set shows the correlation between AKT2 expression and the overall survival or progression-free survival in LUAD (c, $\mathbf{d}$ ) and LUSC (e, $\mathbf{f}$ ) patients. $\mathbf{g}$ and $\mathbf{h}$ Public data from TIMER database shows the correlation between AKT2 expression and overall survival in LUAD (g) and LUSC (h) patients. OS, overall survival; PFS, progression-free survival. ${ }^{*} P<0.05$; ${ }^{*} P<0.01$; ${ }^{* *} P<0.001$ 


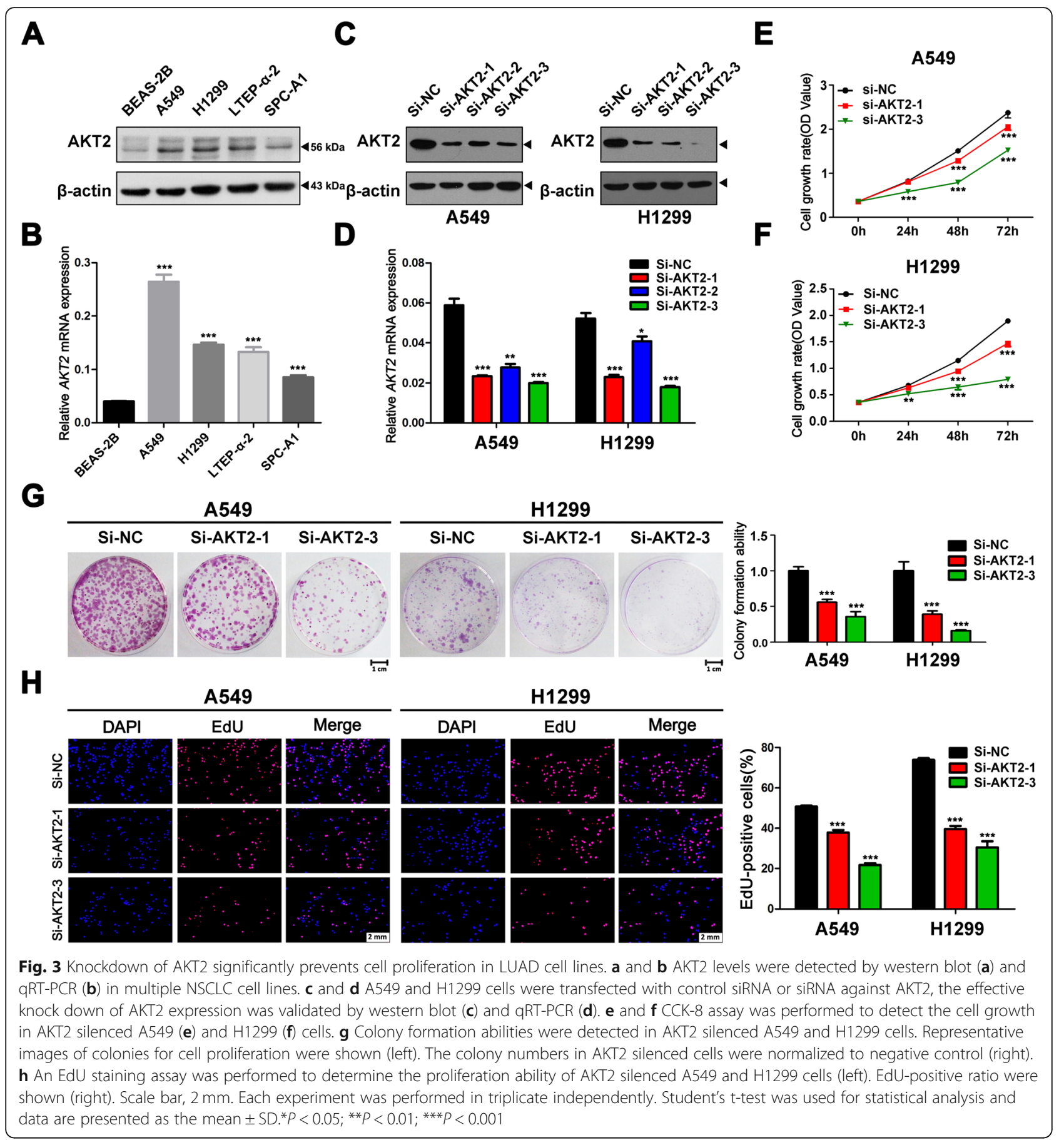

of miR-124 and AKT2 in these tumor tissues. The data indicated that miR-124 expression was indeed upregulated, while AKT2 expression was downregulated in the miR-124 agomir treatment group (Fig. 7e and f). Moreover, an immunohistochemical assay was used to evaluate AKT2 and KI67 expression levels in these tumors (Fig. 7g). Compared with the control group, the miR-124 agomir group showed lower protein expression of both
AKT2 and KI67. The results also confirmed that miR124 overexpression could inhibit tumor growth by suppressing the expression of AKT2 in vivo.

\section{Discussion}

AKT2, characterized as a serine/threonine protein kinase, has been proven to facilitate and contribute to tumor development in addition to its roles in 


\section{A}

A549

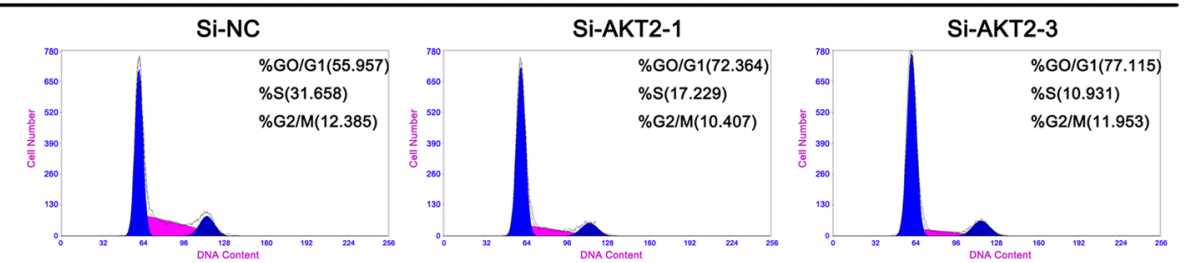

$\mathrm{H} 1299$
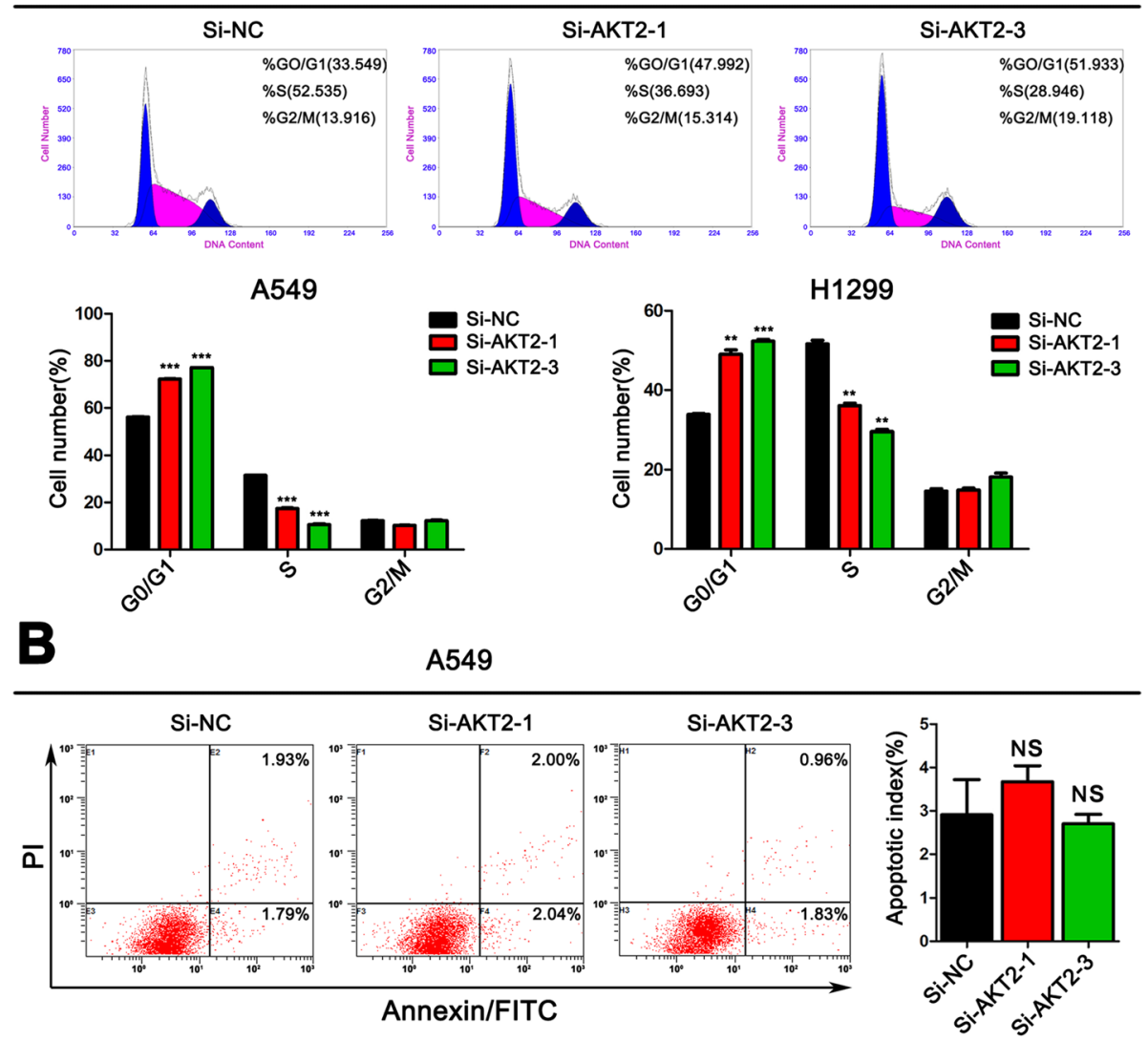

$\mathrm{H} 1299$

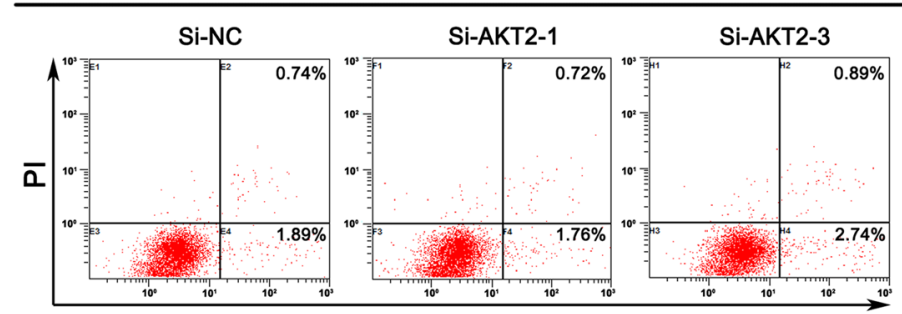

Annexin/FITC

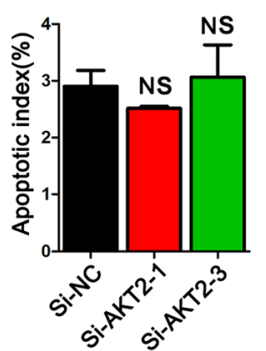

Fig. 4 Silencing AKT2 attenuates the cell cycle progression of LUAD cells without affecting apoptosis. a Flow cytometry cell cycle analysis was performed in A549 and H1299 cells transfected with Si-NC, Si-AKT2-1 and Si-AKT2-3. The distribution (\%) of G0/G1, S and G2/M phases are shown in the histograms (bottom). b Flow cytometry apoptosis assay was performed in A549 and H1299 cells transfected with Si-NC, Si-AKT2-1 and Si-AKT2-3. $48 \mathrm{~h}$ post-transfection, cells were harvested and stained with Annexin V/FITC and propidium iodide (PI). The percentage of apoptotic cells are shown in the right panel. The date values represent mean \pm SD of three measurements independently. NS: no significance. ${ }^{*} P<0.05 ;{ }^{* *} P<0.01 ;{ }^{* * *} P<0.001$ 
A
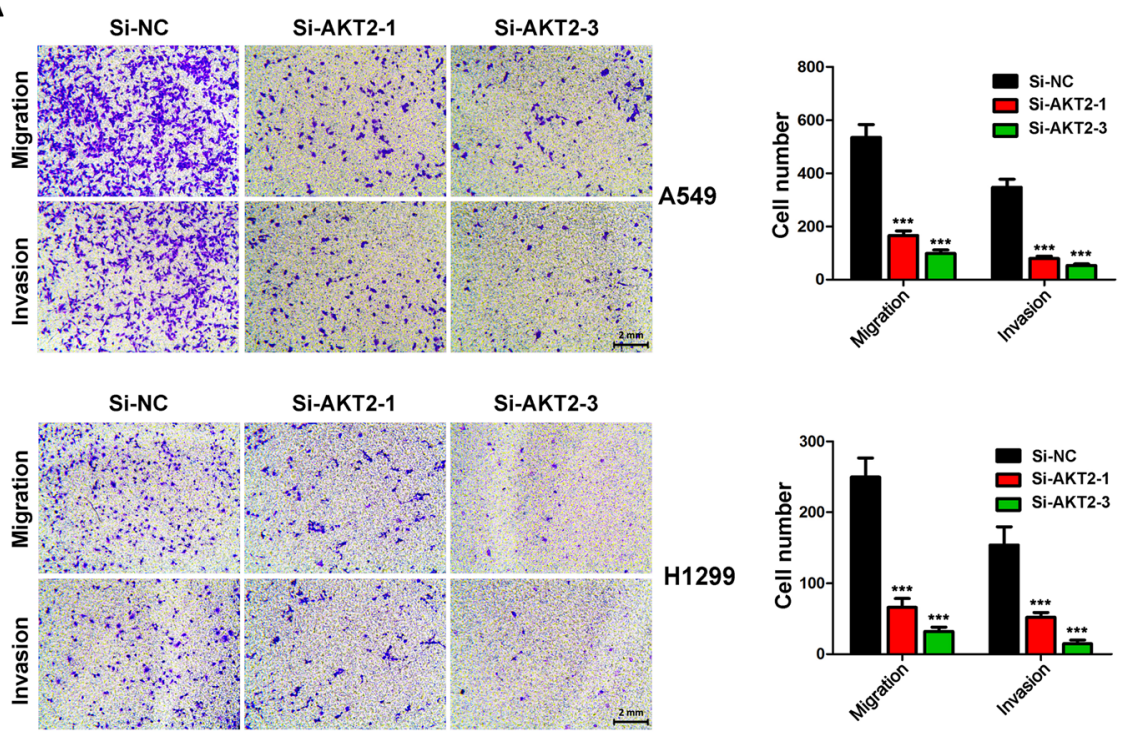

B
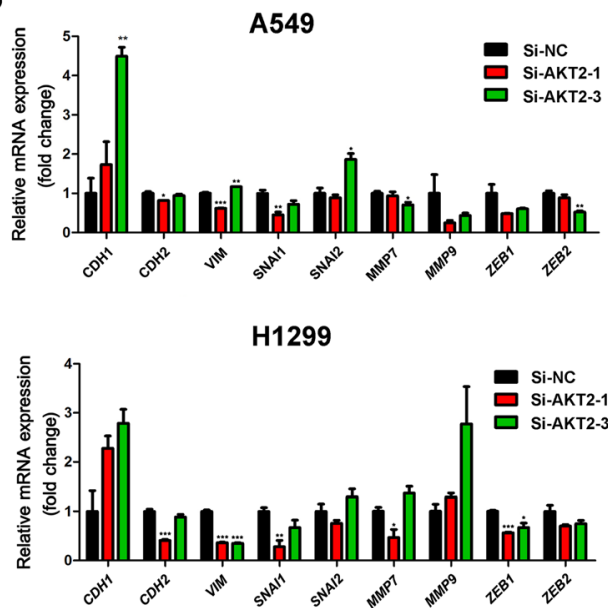

C

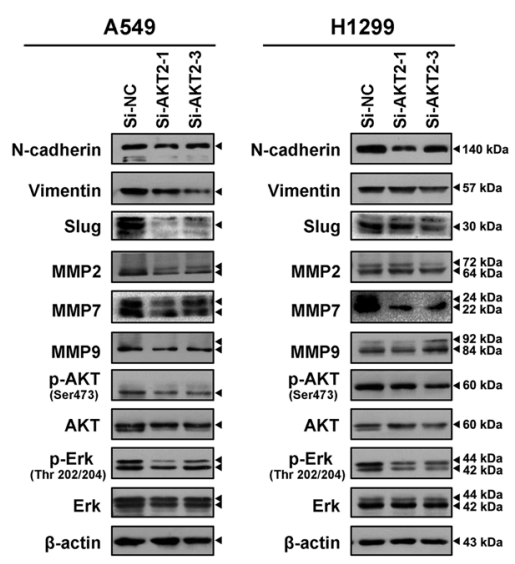

Fig. 5 Depletion of AKT2 inhibits cell migration and invasion in LUAD cells. a AKT2-silenced A549 and H1299 cells were allowed to migrate through an 8- $\mu \mathrm{M}$ pore in Transwells. The migratory cells were stained and counted in at least three microscopic fields. Cells were then treated as above and allowed to invade through the matrigel-coated membrane in the transwell inserts. Invaded cells were stained and counted under a microscope. Representative images (left) and the migratory cell numbers (right) were shown. Scale bar, $2 \mathrm{~mm}$. b The mRNA expression of CDH1, CDH2, VIM, SNAI1, SNAI2, MMP7, MMP9, ZEB1 and ZEB2 were detected by qRT-PCR in AKT2 silenced A549 (upper) and H1299 (bottom) cells. c The expression of N-cadherin, Vimentin, Slug, MMP2, MMP7, MMP9, AKT, p-AKT, Erk and p-Erk protein levels were examined by western blot in AKT2 silenced A549 (left) and H1299 (right) cells. Each experiment was performed in triplicate independently and values are expressed as mean \pm SD. ${ }^{*} P<0.05{ }^{* *} P<0.01{ }^{* * *} P<0.001$

angiogenesis, myoblast differentiation, glucose metabolism and inflammatory disease regulation [24]. AKT2 has been discovered to be overexpressed in human cancer tissues, including lung cancer, breast cancer, and colon cancer tissues [25-27]. An increasing amount of evidence supports that AKT2 can be regarded as a prognostic indicator in cancer patients. In osteosarcoma, AKT2 expression is significantly higher in cancerous tissues than in noncancerous tissues, implying shortened event-free survival and overall survival [28]. In meningiomas, AKT2 expression is negatively correlated with patient recurrence-free survival [29]. In pancreatic cancer, elevated AKT2 expression indicates shortened progression-free survival and overall survival [30]. In our present study, we confirmed that AKT2 is highly expressed in LUAD and closely related to the survival of LUAD patients. Although AKT2 is also highly expressed in lung squamous cell carcinoma, our study found that it was not related to the prognosis of lung squamous cell carcinoma, partially owing to the small sample size of 


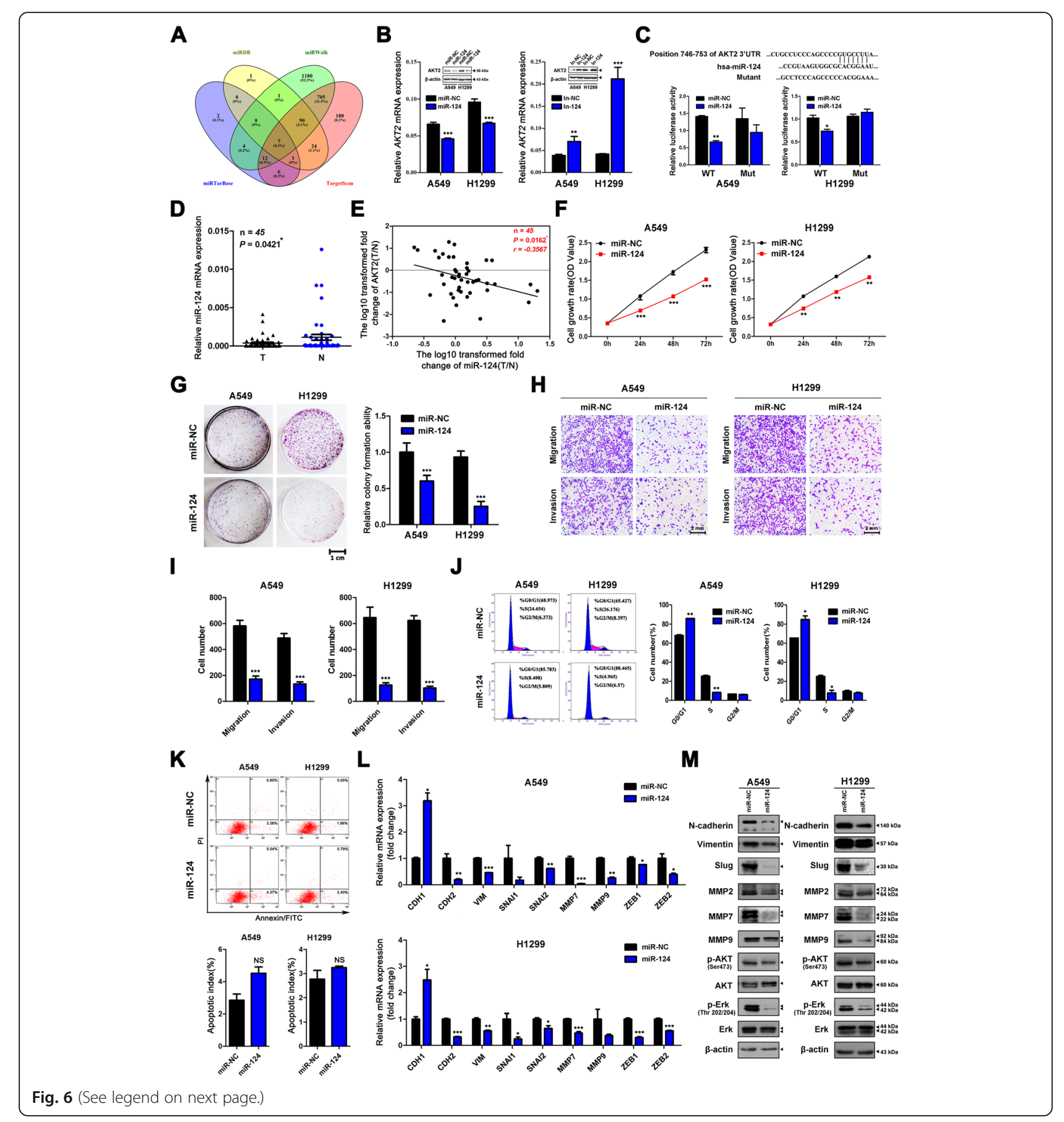




\begin{abstract}
(See figure on previous page.)
Fig. 6 MiR-124 directly binds to AKT2 $3^{\prime} U T R$ region and thus inhibits LUAD cell proliferation, migration and invasion. a Authoritative bioinformatic databases (miRDB, miRWalk, miRTarBase and TargetScan) were used to predict the putative miRNAs targeting AKT2. b After transfection with miR124 mimics and miR-NC (left) or miR-124 inhibitor or inhibitor-NC (right) in A549 and H1299 cell lines, the mRNA and protein levels of AKT2 were analyzed by western blot and qRT-PCR assays. c Computational algorithms predict that AKT2 3'UTR region harbors a putative miR-124 binding site (upper). Reporter vector containing wild type AKT2 3'UTR fragment was constructed, and different mutation was then introduced into the potential miR-124 targeting site to obtain mutant type $3^{\prime} U T R$. The generated luciferase reporter plasmids were co-transfected with negative control (miR-NC) or miR-124 mimics into A549 and H1299 cells. The relative firefly luciferase activity was determined and normalized to the Renilla luciferase activity (bottom). $\mathbf{d}$ qRT-PCR analysis of miR-124 expression in 45 paired NSCLC tissues and adjacent normal tissues. e Kaplanmeier analysis was used to detect the correlation between miR-124 and AKT2 expression in 45 paired NSCLC tissues and adjacent normal tissues. miR-124 and AKT2 mRNA levels are normalized against $U 6$ and $\beta$-actin, respectively. $X$ and $y$ axes represent the $\log _{10}$ transformed T/N expression ratios of miR-124 and AKT2 mRNA, respectively. $\mathbf{f}$ and $\mathbf{g}$ CCK8 $(\mathbf{f})$ and colony formation $(\mathbf{g})$ assays were used to determine the proliferation abilities of miR-124 mimics or negative control (Si-NC) transfected A549 and H1299 cells. $\mathbf{h}$ and $\mathbf{i}$ miR-124 overexpressed A549 and H1299 cells were allowed to migrate through an 8 - $\mu \mathrm{m}$ pore or invade through matrigel-coated membrane in transwells. Migratory and invasive cells were stained and counted in at least three light microscopic fields. Representative images (h) and migratory or invasive cell numbers (i) were shown. Scale bar, 2 mm. $\mathbf{j}$ and $\mathbf{k}$ Flow cytometry cell cycle analysis of A549 and H1299 cell lines after miR-124 overexpression (left). The distribution (\%) of G0/G1, S and G2/M phases are shown in the histograms (right). I and $\mathbf{m}$ Indicated EMT-related mRNAs (I) and proteins ( $\mathbf{m}$ ) were analyzed by qRTPCR and western blot in miR-124 overexpressed A549 and H1299 cells. Each analysis was performed in triplicate and Values are represented as means $\pm S D . * P<0.05 * * P<0.01{ }^{* * *} P<0.001$
\end{abstract}

evaluated patients. On the other hand, there might be other factors that contributed to the differences between the LUAD and LUSC subgroups, but this point needs further study.

As an important downstream component of the PI3K pathway, activated AKT2 can promote the transcription of the downstream substrate rapamycin (mTOR) and transcription factors Forkhead family (FOXO), which is involved in protein synthesis, cell proliferation, metastasis and survival processes [31]. Our study showed that A549 and H1299 cells contained the highest AKT2 expression levels among four adenocarcinoma cell lines tested. Therefore, we chose A549 and H1299 cells to explore the role of AKT2 in LUAD. We silenced AKT2 expression with specific siRNAs in these two cell lines. The results showed that silencing AKT2 expression decreased cell proliferation via cell cycle arrest, while apoptosis was not affected. Moreover, migratory and invasive abilities were inhibited in the AKT2-knockdown group.

Although the role of AKT2 in human cancer has been well established, the specific mechanism of AKT2mediated tumor development remains to be explored. Studies have demonstrated that activated AKT2 can result in transcriptional control, such as the suppression of p21, Bax, Bad and procaspase-9 expression or the promotion of insulin-like growth factor receptor-1 expression [9, 32-35]. Our data showed that the mRNA and protein expression levels of EMT markers (N-cadherin, Vimentin and Slug), MMP7, p-AKT, and p-Erk were consistently decreased after AKT2 knockdown in LUAD cells. Therefore, the results of our current research illustrate the role of AKT2 as a tumor oncogene, promoting cell proliferation and metastasis in LUAD.

Previous studies have proven that AKT2 can be mainly regulated by upstream PI3K and PTEN. In contrast to the stimulatory role of PI3K, PTEN negatively regulates the AKT2 signaling pathway [35]. Apart from this signaling pathway, AKT2 can also be regulated by microRNAs [36]. MicroRNA/mRNA interactions are regarded as a fundamental and epigenetic generegulatory mechanism. Based on the analysis of four bioinformatic databases including miRDB, miRWalk, miRTarBase and TargetScan, seven microRNAs were predicted to potentially bind to AKT2. MiR-124 was found to potentially contribute to AKT2 overexpression. MiR-124 has been reported to play critical roles in tumor formation and development in multiple cancers, such as lung, breast and liver cancer $[16,37,38]$. In liver cancer, miR-124 overexpression reduces the expression of CLIC1, thereby reducing the migration and invasion of liver cancer cells [38]. In lung adenocarcinoma, miR-124 regulates cell proliferation, migration, and invasion by directly targeting SOX9 [23]. However, the potential association between miR-124 and AKT2 in LUAD is unclear. In the current study, we first proved that miR-124 can bind to the wild-type 3 '-UTR but not a mutant $3^{\prime}$-UTR via a luciferase assay. Additionally, we found that the expression of miR-124 in NSCLC tissues was lower than that in normal lung tissues and negatively correlated with AKT2 expression. Then, we overexpressed miR-124 in A549 and H1299 cells to evaluate its effects on proliferation, metastasis and invasion. Our results showed that AKT2 expression could be significantly decreased by miR-124 overexpression. Consistently, CCK-8 and transwell assays confirmed that miR-124 overexpression could significantly reduce cell proliferation, metastasis and invasion. Furthermore, we found that upregulated miR-124 expression could inhibit the expression of EMT markers, MMPs, p-AKT, and p-Erk. Finally, our experimental results were verified in vivo. 


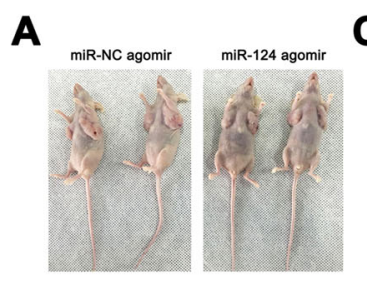

B

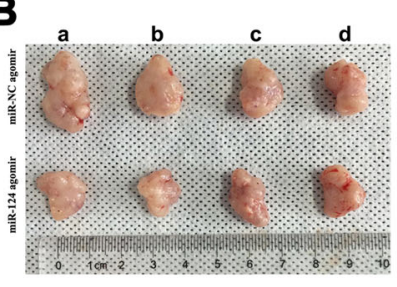

C

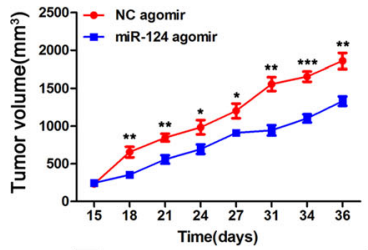

E

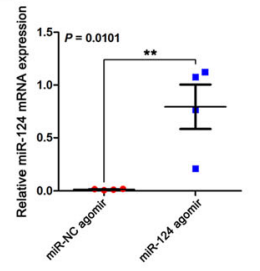

D

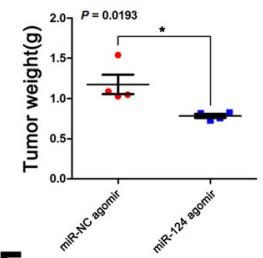

$\mathbf{F}$

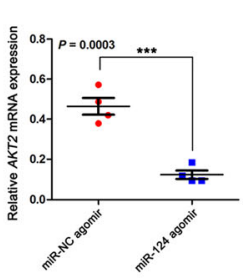

G miR-NC Agomir

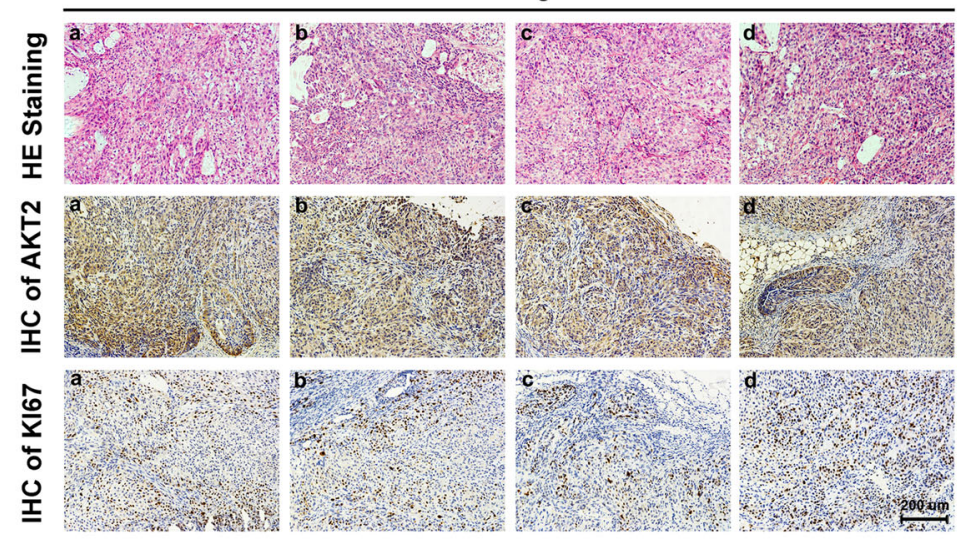

miR-124 Agomir

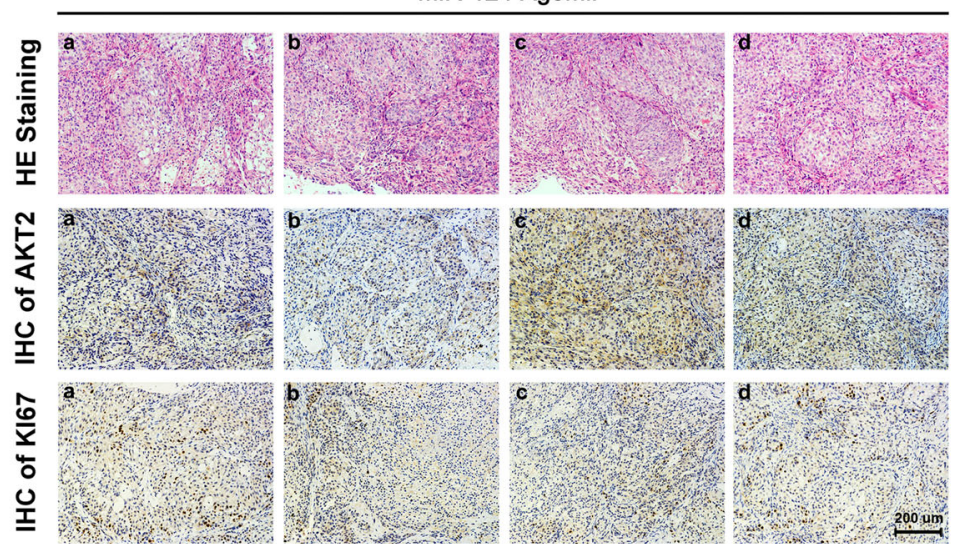

Fig. 7 MiR-124 inhibits tumor growth by targeting AKT2 in vivo. a and $\mathbf{b} 2 \times 10^{6}$ A549 cells were injected into nude mice $(n=2$ mice per group). After tumor formation, miR-124 agomir and miR-NC agomir were injected into each tumor. Thirty-six days later, mice were euthanasia and tumors were surgically resected. Representative images of mice (a) and tumors (b) are shown. c The xenograft tumor volumes were measured every 2-3 days for total 36 days. Graph of tumor growth curves at the experimental endpoint. d Quantification of tumor weights from control and miR-124 agomir group. $\mathbf{e}$ and $\mathbf{f}$ qRT-PCR analysis of miR-124 and AKT2 mRNA expression in each excised tumor. U6 and ACTB were used as internal controls, respectively. $\mathbf{g}$ Representative images of H\&E staining and IHC staining show tumor cells and the expression of AKT2 and KI67 in excised tumors from control or miR-124 agomir group. Scale bar, 200 um. ${ }^{*} P<0.05{ }^{* *} P<0.01{ }^{* * *} P<0.001$ 


\section{Conclusions}

In summary, this study found that AKT2 was highly expressed in LUAD and promoted cell growth, metastasis and invasion. MiR-124 overexpression could negatively regulate AKT2 by binding to the 3 '-UTR of AKT2 mRNA and thus inhibit the occurrence and development of LUAD. Therefore, the miR-124/AKT2 axis may serve as a potential target for novel therapies for LUAD.

\section{Supplementary information}

Supplementary information accompanies this paper at https://doi.org/10. 1186/s12931-020-01491-0.

Additional file 1: Table S1. The sequences of primers used in our study.

Additional file 2: Table S2. Various clinical characteristics and the mRNA expression levels of AKT2 and miR-124 in NSCLC tissues.

Additional file 3. Supplementary original blots.

\section{Abbreviations}

NSCLC: Non-small cell lung cancer; LUAD: Lung adenocarcinoma; LUSC: Lung squamous cell carcinoma; qRT-PCR: Quantitative real-time PCR; HE staining: Hematoxylin and eosin (HE) staining; IHC: Immunohistochemistry; CCK-8: Cell counting kit-8; EMT: Epithelial-mesenchymal transition; MMPs: Matrix metalloproteinases; 3'-UTR: 3'-Untranslated region; TIMER database: Tumor Immune Estimation Resource database; OS: Overall survival; PFS: Progression-free survival; PTEN: Phosphatase and tensin homologue; NC: Negative control; NS: No significance

\section{Acknowledgments}

Not applicable.

\section{Authors' contributions}

$T L$ and JJZ carried out the experiments; WWD and WWN collected patient samples; YZ analyzed the data; YYZ drafted the manuscript; and ZYL and JAH revised the manuscript and provided financial support. The author(s) read and approved the final manuscript.

\section{Funding}

This research was funded by the National Natural Science Foundation of China (No. 81802885), the Foundation of Health Care Rejuvenation by Science and Education (No. KJXW2016003), the Societal and Developmental Project of Suzhou (No. SS201630), the Suzhou Key Laboratory for Respiratory Medicine (No. SZS201617), the Clinical Medical Center of Suzhou (No. Szzx201502) and the Jiangsu Provincial Key Medical Discipline (No. ZDXKB2016007)

\section{Availability of data and materials}

The datasets used and/or analyzed during the current study are available from the corresponding author on reasonable request.

\section{Ethics approval and consent to participate}

Each patient involved in the research signed a written informed consent form, and this study was approved by the Ethics Committee and Institutional Review Board of the First Affiliated Hospital of Soochow University. All animal experiments were carried out in accordance with the Guide for the Care and Use of Experimental Animals from the Experimental Animal Center of Soochow University.

\section{Consent for publication}

Not applicable.

\section{Competing interests}

The authors declare no conflicts of interest.

\section{Author details}

'Department of Respiratory Medicine, the First Affiliated Hospital of Soochow University, Suzhou 215006, China. ${ }^{2}$ Suzhou Key Laboratory for Respiratory Diseases, Suzhou 215006, China. ${ }^{3}$ Institutes of Biology and Medical Sciences, Soochow University, Suzhou 215123, China. ${ }^{4}$ Institute of Respiratory Diseases, Soochow University, Suzhou 215006, China.

Received: 18 April 2020 Accepted: 18 August 2020

Published online: 01 September 2020

\section{References}

1. Siegel RL, Miller KD, Jemal A. Cancer statistics, 2019. CA Cancer J Clin. 2019; 69:7-34.

2. Herbst RS, Morgensztern D, Boshoff $C$. The biology and management of non-small cell lung cancer. Nature. 2018:553:446-54.

3. Mulshine $J \mathrm{~L}$, Sullivan DC. Clinical practice. Lung cancer screening. N Engl J Med. 2005;352:2714-20.

4. Hers I, Vincent EE, Tavare JM. Akt signalling in health and disease. Cell Signal. 2011;23:1515-27.

5. Brazil DP, Hemmings BA. Ten years of protein kinase B signalling: a hard Akt to follow. Trends Biochem Sci. 2001;26:657-64.

6. Li H, Lu S, Chen Y, Zheng L, Chen L, Ding H, et al. AKT2 phosphorylation of hexokinase 2 at T473 promotes tumorigenesis and metastasis in colon cancer cells via NF-kappaB, HIF1alpha, MMP2, and MMP9 upregulation. Cell Signal. 2019;58:99-110

7. Gener P, Rafael D, Seras-Franzoso J, Perez A, Pindado LA, Casas G, et al. Pivotal role of AKT2 during dynamic phenotypic change of breast cancer stem cells. Cancers (Basel). 2019;11:1058.

8. Sahlberg SH, Gustafsson AS, Pendekanti PN, Glimelius B, Stenerlow B. The influence of AKT isoforms on radiation sensitivity and DNA repair in colon cancer cell lines. Tumour Biol. 2014;35:3525-34.

9. Lu Z, Wang M, Wu S, Ye M, Lin Z, Shun T, et al. MicroRNA-137-regulated AKT serine/threonine kinase 2 inhibits tumor growth and sensitizes cisplatin in patients with non-small cell lung cancer. Oncol Lett. 2018;16:1876-84.

10. Filipowicz W, Bhattacharyya SN, Sonenberg N. Mechanisms of posttranscriptional regulation by microRNAs: are the answers in sight? Nat Rev Genet. 2008:9:102-14.

11. Li Z, Rana TM. Therapeutic targeting of microRNAs: current status and future challenges. Nat Rev Drug Discov. 2014;13:622-38.

12. Hou L, Zhao $Y$, Song GQ, Ma YH, Jin XH, Jin SL, et al. Interfering cellular lactate homeostasis overcomes Taxol resistance of breast cancer cells through the microRNA-124-mediated lactate transporter (MCT1) inhibition. Cancer Cell Int. 2019;19:193.

13. Li M, Wan G, Yu H, Xiong W. High-intensity focused ultrasound inhibits invasion and metastasis of colon cancer cells by enhancing microRNA-124mediated suppression of STAT3. FEBS Open Bio. 2019;9:1128-36.

14. Meng Y, Shang F, Zhu Y. miR-124 participates in the proliferation and differentiation of brain glioma stem cells through regulating Nogo/NgR expression. Exp Ther Med. 2019;18:2783-8.

15. Kim J, Jeong D, Nam J, Aung TN, Gim JA, Park KU, et al. MicroRNA-124 regulates glucocorticoid sensitivity by targeting phosphodiesterase $4 \mathrm{~B}$ in diffuse large B cell lymphoma. Gene. 2015;558:173-80.

16. Qi MM, Ge F, Chen XJ, Tang C, Ma J. MiR-124 changes the sensitivity of lung cancer cells to cisplatin through targeting STAT3. Eur Rev Med Pharmacol Sci. 2019;23:5242-50

17. Kosti A, Du L, Shivram H, Qiao M, Burns S, Garcia JG, et al. ELF4 is a target of miR-124 and promotes neuroblastoma proliferation and undifferentiated state. Mol Cancer Res. 2020;18:68-78.

18. Fu W, Wu X, Yang Z, Mi H. The effect of miR-124-3p on cell proliferation and apoptosis in bladder cancer by targeting EDNRB. Arch Med Sci. 2019;15: 1154-62.

19. Jin H, Li Q, Cao F, Wang SN, Wang RT, Wang Y, et al. miR-124 Inhibits Lung Tumorigenesis Induced by K-ras Mutation and NNK. Mol Ther Nucleic Acids. 2017;9:145-54.

20. Zhao X, Lu C, Chu W, Zhang B, Zhen Q, Wang R, et al. MicroRNA-124 suppresses proliferation and glycolysis in non-small cell lung cancer cells by targeting AKT-GLUT1/HKII. Tumour Biol. 2017;39:1010428317706215.

21. Ling C, Wang X, Zhu J, Tang H, Du W, Zeng Y, et al. MicroRNA-4286 promotes cell proliferation, migration, and invasion via PTEN regulation of the PI3KJAkt pathway in non-small cell lung cancer. Cancer Med. 2019;8: 3520-31. 
22. Zhu J, Zeng Y, Li W, Qin H, Lei Z, Shen D, et al. CD73/NT5E is a target of miR-30a-5p and plays an important role in the pathogenesis of non-small cell lung cancer. Mol Cancer. 2017;16:34.

23. Wang X, Liu Y, Liu X, Yang J, Teng G, Zhang L, et al. MiR-124 inhibits cell proliferation, migration and invasion by directly targeting SOX9 in lung adenocarcinoma. Oncol Rep. 2016;35:3115-21.

24. Vergadi E, leronymaki E, Lyroni K, Vaporidi K, Tsatsanis C. Akt signaling pathway in macrophage activation and M1/M2 polarization. J Immunol. 2017:198:1006-14.

25. Attoub S, Arafat K, Kamel Hammadi N, Mester J, Gaben AM. Akt2 knockdown reveals its contribution to human lung cancer cell proliferation, growth, motility, invasion and endothelial cell tube formation. Sci Rep. 2015; 5:12759.

26. Santi SA, Lee H. Ablation of Akt2 induces autophagy through cell cycle arrest, the downregulation of p70S6K, and the deregulation of mitochondria in MDA-MB231 cells. PLoS One. 2011;6:e14614.

27. Martini M, De Santis MC, Braccini L, Gulluni F, Hirsch E. PISK/AKT signaling pathway and cancer: an updated review. Ann Med. 2014;46:372-83.

28. Zhu Y, Zhou J, Ji Y, Yu B. Elevated expression of AKT2 correlates with disease severity and poor prognosis in human osteosarcoma. Mol Med Rep. 2014;10:737-42.

29. Wang Q, Fan SY, Qian J, Wang JY, Lu YC, Hu GH, et al. AKT2 expression in histopathologic grading and recurrence of meningiomas. Eur J Surg Oncol. 2014;40:1056-61.

30. Banno E, Togashi Y, de Velasco MA, Mizukami T, Nakamura Y, Terashima M, et al. Clinical significance of Akt2 in advanced pancreatic cancer treated with erlotinib. Int J Oncol. 2017;50:2049-58.

31. Wickenden JA, Watson CJ. Key signalling nodes in mammary gland development and cancer. Signalling downstream of PI3 kinase in mammary epithelium: a play in 3 Akts. Breast Cancer Res. 2010;12:202.

32. Bai Y, Li J, Liu Y, Zhang B. MiR-615 inhibited cell proliferation and cell cycle of human breast cancer cells by suppressing of AKT2 expression. Int J Clin Exp Med. 2015:8:3801-8.

33. Wu L, Chen J, Ding C, Wei S, Zhu Y, Yang W, et al. MicroRNA-137 contributes to dampened tumorigenesis in human gastric Cancer by targeting AKT2. PLoS One. 2015;10:e0130124.

34. Li X, Li Z, Zhou W, Xing X, Huang L, Tian L, et al. Overexpression of 4EBP1, p70S6K, Akt1 or Akt2 differentially promotes Coxsackievirus B3-induced apoptosis in HeLa cells. Cell Death Dis. 2013;4:e803-9.

35. Chin YR, Yuan X, Balk SP, Toker A. PTEN-deficient tumors depend on AKT2 for maintenance and survival. Cancer Discov. 2014;4:942-55.

36. Honardoost M, Rad S. Triangle of AKT2, miRNA, and tumorigenesis in different cancers. Appl Biochem Biotechnol. 2018;185:524-40.

37. Yan G, Li Y, Zhan L, Sun S, Yuan J, Wang T, et al. Decreased miR-124-3p promoted breast cancer proliferation and metastasis by targeting MGAT5. Am J Cancer Res. 2019;9:585-96.

38. Yue X, Cui Y, You Q, Lu Y, Zhang J. MicroRNA124 negatively regulates chloride intracellular channel 1 to suppress the migration and invasion of liver cancer cells. Oncol Rep. 2019;42:1380-90.

\section{Publisher's Note}

Springer Nature remains neutral with regard to jurisdictional claims in published maps and institutional affiliations.

Ready to submit your research? Choose BMC and benefit from:

- fast, convenient online submission

- thorough peer review by experienced researchers in your field

- rapid publication on acceptance

- support for research data, including large and complex data types

- gold Open Access which fosters wider collaboration and increased citations

- maximum visibility for your research: over $100 \mathrm{M}$ website views per year

At BMC, research is always in progress.

Learn more biomedcentral.com/submissions 